\title{
A survey on foot drop and functional electrical stimulation
}

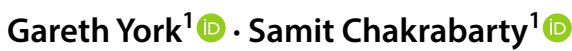

Received: 21 November 2018 / Accepted: 1 March 2019 / Published online: 13 March 2019

(c) The Author(s) 2019

\begin{abstract}
The weakness of the lower leg muscles due to nerve damage or muscle weakness can result in foot drop, a change in gait that manifests as an inability to lift the toes of the foot when walking. Foot drop results in a decreased quality of life, with unassisted movement becoming difficult or impossible. The increased risk of falls is particularly problematic as foot drop often affects the elderly or infirm for whom falling already presents a great danger. Current treatment options include fixed ankle-foot orthosis (AFO) aiming to provide rigid support to the foot if the impairment is mild or surgical intervention and functional electrical stimulation (FES) devices if the weakness is more severe. FES intervention is effective for providing a non-invasive treatment in even severe cases of foot drop. Limitations of current models relate to the non-naturalistic recreation of gait in the affected leg and its unsuitability for patients with extensive peripheral nerve damage. Although there are attempts to enhance integration of sensory information and mimic natural stimulation patterns, the focus on restoring a natural feedback loop is still amiss. Without such a closed loop feedback, restoration of a natural gait pattern is unlikely to occur. We here recommend, integration of motor output from multiple muscles, information about the inputs from higherorder controllers, recorded from the intact leg with a closed loop system to improve the effectiveness of FES.
\end{abstract}

Keywords Foot drop $\cdot$ Motor control · Ankle-foot orthosis $\cdot$ Functional electrical stimulation

$\begin{array}{ll}\text { Abbreviations } \\ \text { AFO } & \text { Ankle-foot orthosis } \\ \text { CNS } & \text { Central nervous system } \\ \text { FES } & \text { Functional electrical stimulation } \\ \text { EMG } & \text { Electromyography } \\ \text { ODFS } & \text { Odstock dropped foot stimulator } \\ \text { ANN } & \text { Artificial neural network }\end{array}$

\section{Introduction to foot drop}

The weakness of the dorsiflexor muscles of the leg and foot resulting in gait abnormality is commonly referred to as "foot drop" (Stewart 2008; Stevens et al. 2015). Foot drop is usually unilateral, with bilateral symptoms indicating a more serious injury to the lower spinal segments (Kertmen et al. 2015). It presents during walking as a dragging of the foot or

Samit Chakrabarty

S.Chakrabarty@leeds.ac.uk

Gareth York

bsgjry@leeds.ac.uk

1 School of Biomedical Sciences, Faculty of Biological Sciences, University of Leeds, Leeds LS2 9JT, UK an unusually high stepping motion as a coping mechanism to avoid dragging. The severity and the cause of the condition vary, affecting the effectiveness of treatment options. Temporary or reversible foot drop is often associated with external nerve compression due to poor occupational practices and work environment resulting in prolonged pressure to the back of the knee, such as when crossing the legs or work requiring frequent and prolonged squatting (Woltman 1929; Berry and Richardson 1976; Koller and Blank 1980). Removing the source of pressure often alleviates symptoms, although the recovery can be delayed from days to months. Permanent cases of foot drop are instead due to damage to the peroneal nerve, including injury at a more proximal site to the sciatic nerve, or the muscles these nerves innervate as is the case with muscular dystrophy.

Treatment options depend on the severity and nature of the condition. Following a diagnosis sometimes a simple change in behaviour can remedy the symptoms. For cases of intermittent or very mild foot drop a change in shoes to a flatter sole or a pair of stiff boots can provide all treatment required (Stewart 2008). Traumatic injury to the leg, including direct laceration, occlusion of the nerve due to bone fracture, dislocation, displacement and entrapment of the nerve, can all result in permanent or more severe foot 
drop. Foot drop is very commonly caused by a severe and sudden sprain or twisting of the ankle due to damage from the immense torsional force acting on the nerve at the back of the knee (Nobel 1966). Increased internal pressure caused by swelling, internal masses can also result in permanent foot drop, although reversible depending on the swiftness of intervention. Benign masses at the level of the knee, such as Baker's cysts, outgrowth of nerve ganglia at the tibiofibular joint (Brooks 1952; Nakano 1978), malignant tumours can all result in nerve compression is located at a vulnerable site, like the fibular head (Suh et al. 1992) leading to foot drop. Impairment of the central nervous system (CNS) because of injury, swelling or stroke can also result in foot drop but is usually one of many symptoms of the more complex pathophysiology of the injury. These cases require a device capable of more pronounced gait correction. The options offered to patients in the UK via the NHS are physiotherapy, ankle-foot orthosis (AFO), surgery to fuse ankle and foot bones, tendon transfer surgery from lower leg muscles that are still sufficiently active and functional electrical stimulation devices (FES).

\section{Current treatment options}

Physiotherapy focuses on exercises to strengthen specific muscles when foot drop is relatively limited and suspected to be due to muscle weakness (Potenza et al. 2012). The advantages of physiotherapy are it's low-cost, and a lack of negative impact on patient life; with long-term efficacy as the patient can continue exercising the foot at home easily, past the initial consultation. Limited physiotherapy is advised for most patients with the moderate to severe foot drop, but its effects are limited by the patient's ability to exercise the muscles in question. Muscle weakness due to nerve damage is unlikely to see significant improvements due to the general inability for the peripheral nervous system to regenerate (Ding et al. 2005).

Ankle Foot Orthosis is the most commonly prescribed treatment, being relatively cheap and effectively alleviating most gait abnormalities (Kluding et al. 2013). The precise design of the orthotic varies but generally consists of a fixed cuff, around the ankle or mid-shin, attached to braces cradling the sole of the foot. These devices are designed to provide mechanical support and physically prevent the foot from dragging during the gait cycle as seen in Fig. 1a.

In combination with exercise, frequent use of AFO can reduce the risk of falls while improving mobility. Despite this, AFO is not an ideal solution as most AFOs are large and difficult to conceal completely under clothing. The weight of these devices increases proportionally to the support the device offers making them bulkier and less appealing to wear, and with an increased likelihood of painful rubbing of the skin. Furthermore, whilst these devices correct the initial abnormality, preventing the foot from dropping, the foot is forced into a $90^{\circ}$ position, an equally unnatural position for normal walking. AFO treats the symptom of foot drop but not the cause. A variety of products are currently available, which help cover some of these flaws, however, the existence of the large market for orthoses suggests that no one product adequately addresses these flaws successfully.

Tendon transfer surgery can prove very effective in certain cases but requires that some ankle function is still intact. A portion of the remaining active muscles tendons is transferred to another attachment point, typically towards the front of the foot. This inherently only alters where the site of weakness is, as the transferred muscles are now unable to perform their original function. Although this does correct the foot drop it comes at the cost of weakness in other areas. The unpredictability of the outcome of the surgery means that some patients will still require AFO even after their surgery.

Midfoot fusion of the bones that make up the arch of the foot can also help correct foot drop. This option is largely a choice of last resort where the foot has lost most of the motion or when the condition additionally presents with severe pain, as the surgery is invasive and eliminates any hope of normal recovery.

Functional electrical stimulation involves stimulating the weakened muscle alone or combined with the associated peroneal nerve using surface or implanted electrodes, to recruit more muscle fibres to overcome the weakness (Barbeau et al. 1999; Embrey et al. 2010; Kesar et al. 2011; Melo et al. 2015; Ferrante et al. 2016). Fibres are recruited by electrical stimulus pulses delivered through the electrodes. The timing of this stimulus pulse is controlled in a variety of ways; by the user with a handheld switch, pressure sensors in the shoe or by electromyography (EMG) signals recorded from the leg. In all cases, the aim is for stimulation to start when the foot lifts off the ground and cease when the device detects the foot strike phase during the gait cycle as shown in Fig. 1a (Melo et al. 2015). The device design is usually simple, with a single cuff situated just below the knee, and is, therefore, smaller and easier to conceal. Electrodes can be built into the device or can be separately situated to better target the stimulation site.

FES is particularly appealing as it is the one treatment option besides physiotherapy that can help correct the cause of the condition to a stage where treatment may no longer be required. Whilst it is uncommon, a proportion of patients using FES devices report their foot drop improving to the point where they no longer require any treatment at all. Furthermore, the gait correction that FES provides can be tuned to produce more natural movement and can result in recovery of additional function, such as raising of the toe, which AFO and surgery do not address (Ridding et al. 2000). 


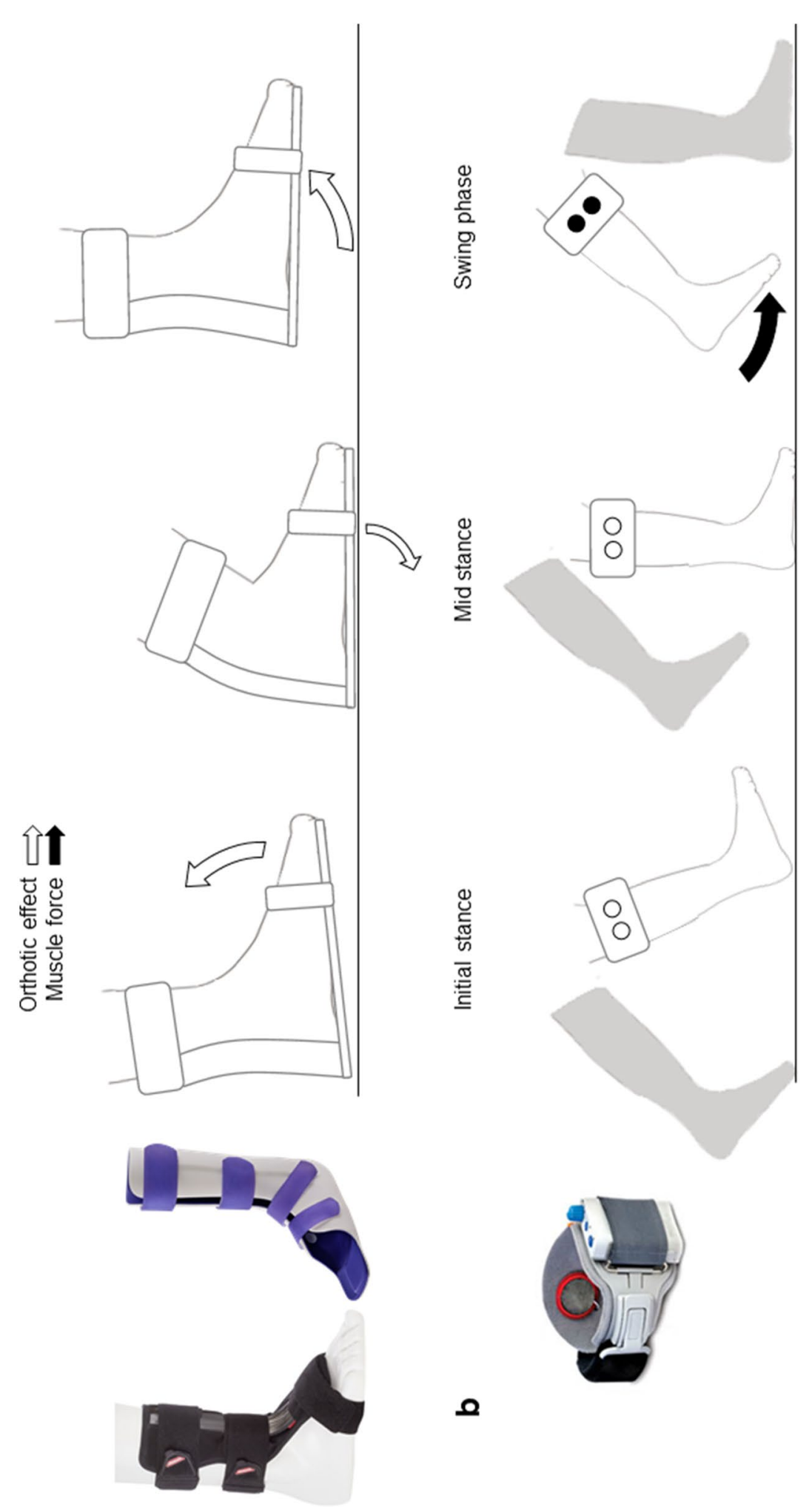

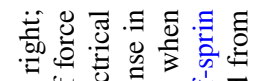

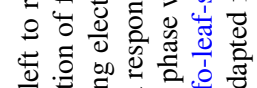

记

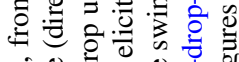

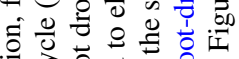

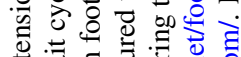

品

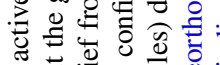

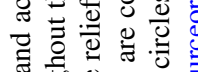

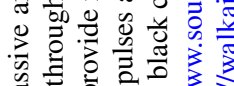

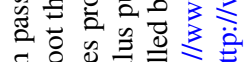

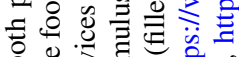

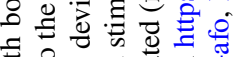

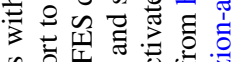

ơ 인.

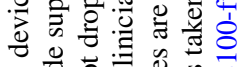

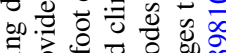

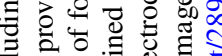

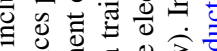

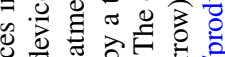

O०

언은

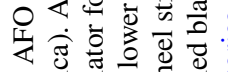

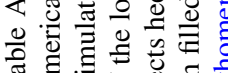

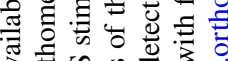

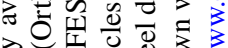

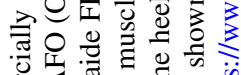

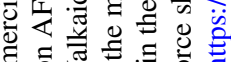

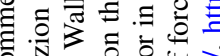

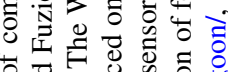

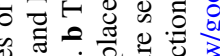

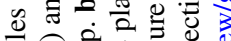

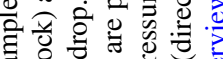

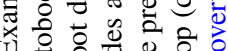

๙

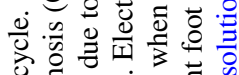

U.

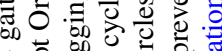

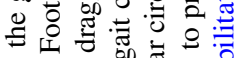

- 0 出

要定过

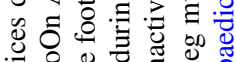

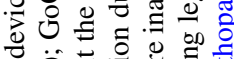

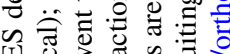

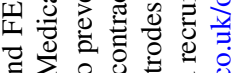

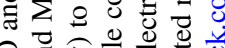

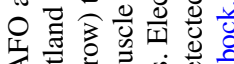

«

흥

者.

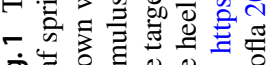

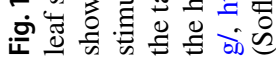


Randomised control trials show that footfall patients using an FES device walk 16\% faster, and have improved quality of walking, with decreased risk of falling and a significant increase in quality of life, compared to other therapies (Kottink et al. 2007).

However, FES is not an option in patients with widespread or severe neural degeneration such as patients with mid-stage-MS, as it requires residual nerve connections to recruit. Another major drawback to FES devices is the cost of the device. Whereas AFO cost varies around $~ £ 80$, not including fitting and assessment, FES devices can cost thousands of pounds over their significantly short lifespan (Taylor et al. 2007; NICE 2016). This is why only some health authorities provide FES by default for patients with foot drop despite the guidelines published by the National Institute for Health and Care Excellence (NICE), often quoting cost and insufficient evidence of improvement compared to AFO devices (Cambridgeshire and Peterborough Clinical Commissioning Group 2013). NICE calculate that over the 5 -year lifespan of the device the total cost of an FES device and consumables will reach $£ 3320$ not including consultation or repairs required. Table 1 provides a direct comparison between the effectiveness of FES and AFO devices. The main findings demonstrate significant increases in walking speed for both FES and AFO but few studies demonstrate a conclusive advantage between either device (Kottink et al. 2007; Everaert et al. 2013; Kluding et al. 2013). Despite this, patients express a clear preference for FES devices primarily due to the ease of concealment (Kottink et al. 2007; Bulley et al. 2011; Kluding et al. 2013). Improvements outside walking speed are more difficult to measure and have largely been neglected in other reviews on the topic. Clearly current devices provide an effective treatment option, however, there is a missed potential in targeting motor recovery as a means of providing a meaningful advantage over AFO.

There are a variety of suppliers of FES devices for foot drop to the NHS in England and Wales, but the largest distributor is Odstock and the most commonly provided device is the Odstock Dropped Foot Stimulator (ODFS) Pace (NICE 2009, 2016). ODFS Pace uses a sensor in the shoe to detect foot lift off, with the stimulation parameters determined during initial consultation by a clinician. The tunable parameters include pulse amplitude (10-100 mA), pulse frequency $(0-60 \mathrm{~Hz})$, pulse width $(0-360 \mu \mathrm{s})$ total output time (0-6 s) and time from zero to max amplitude $(0-2 \mathrm{~s})$. This provides a wide variety of pulses within a safe working range which are representative of the capabilities of most FES devices; repeating trapezoidal stimulation pulses to generate tetanic contraction (Melo et al. 2015). Whilst this method can achieve a close to normal walking pattern compared to an AFO device its key flaw is that it does not incorporate any information regarding the muscle activity produced. The aim of these devices is limited to alleviating gait deficiencies without discomfort and the long-term effectiveness is limited in turn. There is an opportunity to significantly increase the effectiveness of devices currently available by switching aim towards a more ambitious recreation of normal motor activity. Promising advancements in the field of prosthetics have demonstrated dynamic control of a powered lower-limb prosthetic using EMGs (Wen et al. 2017; Spanias et al. 2018). A similar approach used to control stimulation could create a system that directly integrates motor output into an FES device. Stimulation algorithms utilizing muscle synergy information has been shown to produce superior walking motion than stimulation based off foot strike alone (Ferrante et al. 2016). This concept could be extended to target synergistic muscles in cases of severe weakness or paralysis, causing greater activation of weakened pathways through synergistic recruitment. More sophisticated devices such as the WalkAide are already moving in this direction by incorporating tilt sensors to better target the onset and offset of stimulation to time-points in the gait cycle (Stein et al. 2008; Everaert et al. 2013). The WalkAide has similar set-up requirements to the ODFS Pace requiring a clinician to initially set and program stimulation parameters. However, there is also the option for automated assessment of when to activate stimulation during the gait cycle, a feature which should be expanded upon in future iterations to include the dynamic adjustment to stimulation control. Whilst this inclusion of feedback regarding limb position through the tilt sensor is a step in the right direction, this approach is still lacking elements of a closed-loop control system. In the next section, we will describe a way in which a closed-loop system could be implemented with only minor changes to currently available devices.

\section{Improving the efficacy of FES by changing the aim of treatment}

Ferrante et al. (2016) showed that using FES defined by the muscle synergy information from healthy patients resulted in the recovery of a healthier muscle synergy pattern in patients with foot drop. However, in this study analysis of synergies was only performed after treatment, with no update to the stimulation strategy throughout the treatment. Furthermore, the target for the stimulation algorithm was to match the pulse width to that determined by the reconstructed muscle synergies, without any comparison of the actual motor output generated by the stimulation pulse. Whilst this strategy has promising results without integrating motor output the device still falls short of a closed feedback loop. Synergy analysis can be computationally intensive, however, careful algorithm design or implementation of an FPGA-based microprocessor make online analysis a possibility (Rasool et al. 2016; Franco et al. 2017). The method described by 
Table 1 Improvement to walking speed, safety and patient's preference for ankle foot orthotics and three popular functional electrical stimulation devices for the treatment of foot drop in patients with stroke

\begin{tabular}{|c|c|c|c|c|}
\hline Device & Studies covered & Cost $/ £$ & Main walking findings & Main safety findings \\
\hline $\mathrm{AFO}$ & $\begin{array}{l}\text { Kottink et al. (2007); } \\
\text { Everaert et al. } \\
\text { (2013)*; Kluding } \\
\text { et al. (2013); }\end{array}$ & $£ 20-120$ & $\begin{array}{l}\text { Kottink (26-week intervention): } \\
\text { Increased walk speed over } 10 \mathrm{~m} \text { of } 0.07 \mathrm{~ms}^{-1} \\
\text { compared to no device } \\
\text { No change in 6-min walk test } \\
\text { Everaert (12-week intervention): } \\
\text { Increased walk speed through figure } 8 \text { of } \\
0.116 \mathrm{~ms}^{-1} \text { compared to no device } \\
\text { Increased walk speed over } 10 \mathrm{~m} \text { of } 0.117 \\
\text { compared to no device } \\
\text { Kluding ( } 30 \text {-week intervention): } \\
\text { Increase comfortable walk speed of } \\
0.15 \mathrm{~ms}^{-1} \text { compared to before treatment } \\
\text { Increased fast walk speed of } 0.17 \mathrm{~ms}^{-1} \mathrm{com} \text { - } \\
\text { pared to before treatment }\end{array}$ & $\begin{array}{l}\text { Kluding: } \\
\text { No significant difference in falls between AFO } \\
\text { and NESS L300 } \\
50 \text { adverse events related to device use }\end{array}$ \\
\hline ODSTOCK & $\begin{array}{l}\text { Kottink et al. (2007); } \\
\text { Bulley et al. (2011); } \\
\text { Taylor et al. (2007)* }\end{array}$ & $£ 3320$ & $\begin{array}{l}\text { Kottink (26-week intervention): } \\
\text { Increased walk speed over } 10 \text { m of. } 21 \mathrm{~ms}^{-1} \\
\text { compared to AFO with FES and without } \\
(p=0.01) \\
\text { Improvement of } 23 \% \text { in 6-min walk test over } \\
26 \text { weeks ( } p=0.097) \\
\text { Taylor ( } 11 \text {-year medical record review): } \\
\text { Continued use of FES device increased walk } \\
\text { speed over } 10 \mathrm{~m} \text { of } 0.11 \mathrm{~ms}^{-1} \text { with the } \\
\text { device turned off and a further increase of } \\
0.08 \mathrm{~ms}^{-1} \text { with FES turned on (significant } \\
\text { increases compared to start of treatment } \\
p<0.001 \text { and } p<0.001 \text { respectively) } \\
38 \% \text { of patients increased their functional } \\
\text { walking category over } 16.5 \text { months with } \\
\text { FES and } 26 \% \text { patients improved their walk- } \\
\text { ing category with the device turned off }\end{array}$ & $\begin{array}{l}\text { Taylor: } \\
3 \text { stroke patients discontinued use of the } \\
\text { device due to direct problems with the device } \\
\text { ("found stimulus painful" and "too much } \\
\text { bother" being the listed reasons) }\end{array}$ \\
\hline NESS L300 & Kluding et al. (2013) & $£ 4550$ & $\begin{array}{l}\text { Kluding (30-week intervention): } \\
\text { Increase comfortable walk speed of } \\
0.14 \mathrm{~ms}^{-1} \text { (non-significant improvement } \\
\text { compared to AFO } p=0.78 \text { ) } \\
\text { Increased fast walk speed of } 0.13 \mathrm{~ms}^{-1} \text { (non- } \\
\text { significant improvement compared to AFO } \\
p=0.78 \text { ) }\end{array}$ & $\begin{array}{l}\text { Kluding: } \\
130 \text { adverse events related to device use, with } \\
\text { skin irritation accounting for } 51 \text { of these } \\
\text { events (significant increase in adverse events } \\
\text { compared to AFO } p<0.01 \text { ) }\end{array}$ \\
\hline WalkAide & Everaert et al. (2013)* & $£ 3470$ & $\begin{array}{l}\text { Everaert (12-week intervention): } \\
\text { Increased walk speed through figure } 8 \text { of } \\
0.119 \mathrm{~ms}^{-1} \text { compared to no device (non- } \\
\text { significant improvement compared to AFO } \\
p=0.21 \text { ) } \\
\text { Increased walk speed over } 10 \mathrm{~m} \text { of } \\
0.140 \mathrm{~ms}^{-1} \text { compared to no device (non- } \\
\text { significant improvement compared to AFO } \\
p=0.32 \text { ) }\end{array}$ & $\begin{array}{l}\text { Everaert: } \\
\text { WalkAide users felt significantly safer } \\
\text { after } 12 \text { weeks than those who used AFO } \\
(p=0.037)\end{array}$ \\
\hline
\end{tabular}

AFO and FES devices are commonly used to treat foot drop caused by peroneal nerve damage. The cost and effectiveness of these devices are compared in several studies. These studies investigated changes to walking speed, effects on safety and adverse events and patient's preference between devices. Where possible comparison is reported for both no treatment, AFO and FES separately. Studies where FES is combined with AFO use is marked with asterisk. Cost is reported as the initial cost of the device and relevant consumables over a 5 year period, not including fitting and consultation sessions

$A F O$ ankle foot orthotic, FES functional electrical stimulation

Ferrante could be performed in real time, providing dynamic alteration stimulation based off observed changes in synergy recruitment either via online synergy prediction or through set training periods. By providing dynamic feedback the patient and device will adapt to patient recovery as well as providing more naturalistic movement. However, this stimulation strategy is still limited to controlling just one stimulation parameter, missing much of the customization provided 
by clinicians currently in terms of stimulation amplitude etc. A more in-depth strategy that could control for multiple stimulation parameters could produce more specific responses and better recreate the desired synergies.

Artificial neural networks (ANN) can be trained to learn and predict complex non-linear relationships, Unpublished data from this lab has demonstrated the capability for neural networks to learn stimulation parameters for generating specific EMG signals in the rat hind limb, if extended to the FES devices could theoretically be capable of predicting stimulation parameters in real time on a low power device (Schrauwen et al. 2008). Although this requires recording from a large patient cohort to provide enough generalization across subjects and conditions, combining this with muscle synergy prediction previously described would provide advanced stimulation control in a true-closed loop device. Due to the flexibility of training these networks as the network updates to the observed EMG parameters generated it can generate novel stimulation strategies relying on the simultaneous contraction of separate muscle groups. This could allow for better recruitment of remaining connections in more extensively damaged networks. In the same manner that the network can update to match recovery, the network will also continue to adapt to the degradation of the nervous system thus providing a longer period of improved mobility and quality of life for patients with chronic conditions.

\section{Conclusions}

Due to the diverse causes of foot drop, the optimal treatment plan for the best functional outcome in patients should be personalized. For any given patient combinations of physiotherapy, surgical options, AFO or FES allow clinicians to provide patients with a treatment that suits their specific needs, but all current treatment options emphasise symptomatic treatment with the recovery of motor function being incidental. A change in the perceived purpose of FES devices towards motor recovery could have the potential to provide more curative treatment with positive effects beyond just those experienced during walking. Future development of these devices can take advantage of the great strides being made in machine learning and low powered computation. A closed-loop device with dynamic feedback affecting motor output is more flexible to changes in patient condition, potentially encouraging recovery.

Open Access This article is distributed under the terms of the Creative Commons Attribution 4.0 International License (http://creativeco mmons.org/licenses/by/4.0/), which permits unrestricted use, distribution, and reproduction in any medium, provided you give appropriate credit to the original author(s) and the source, provide a link to the Creative Commons license, and indicate if changes were made.

\section{References}

Barbeau, H., et al.: Tapping into spinal circuits to restore motor function. Brain Res Rev 30(1), 27-51 (1999). https://doi.org/10.1016/ S0165-0173(99)00008-9

Berry, H., Richardson, P.M.: Common peroneal nerve palsy: a clinical and electrophysiological review. J Neurol Neurosurg Psychiatry 39(12), 1162-1171 (1976). https://doi.org/10.1136/ jnnp.39.12.1162

Brooks, D.M.: Nerve Compression by Simple Ganglia. J. Bone Joint Surg. 34B(3), 391-400 (1952). https://online.boneandjoint.org. uk/doi/pdf/10.1302/0301-620x.34b3.391 (Accessed 21 October 2018)

Bulley, C., et al.: User experiences, preferences and choices relating to functional electrical stimulation and ankle foot orthoses for footdrop after stroke. Physiotherapy 97(3), 226-233 (2011). https:// doi.org/10.1016/J.PHYSIO.2010.11.001

Cambridgeshire and Peterborough Clinical Commissioning Group: Functional electrical stimulation (FES) for the treatment of drop foot of neurological origin. (2013) https://doi.org/10.1002/14651 858.cd006676.pub2

Ding, Y.M., Kastin, A.J., Pan, W.H.: Neural plasticity after spinal cord injury. Curr Pharm Des 11(11), 1441-1450 (2005). https://doi. org/10.2174/1381612053507855

Embrey, D.G., et al.: Functional electrical stimulation to dorsiflexors and plantar flexors during gait to improve walking in adults with chronic hemiplegia. Arch Phys Med Rehabil 91(5), 687-696 (2010). https://doi.org/10.1016/j.apmr.2009.12.024

Everaert, D.G., et al.: Effect of a foot-drop stimulator and ankle-foot orthosis on walking performance after stroke. Neurorehabilit Neural Repair 27(7), 579-591 (2013). https://doi.org/10.1177/15459 68313481278

Ferrante, S., et al. (2016): A personalized multi-channel FES controller based on muscle synergies to support gait rehabilitation after stroke. Front. Neurosci. 10, 425 (2016). https://doi.org/10.3389/ fnins.2016.00425. https://www.frontiersin.org/articles/10.3389/ fnins.2016.00425/full

Franco, G. et al.: FPGA-based muscle synergy extraction for surface EMG gesture classification. In: 2017 IEEE Biomedical Circuits and Systems Conference (BioCAS), pp. 1-4, (2017). https://doi. org/10.1109/biocas.2017.8325232

Kertmen, H., et al.: Acute bilateral isolated foot drop: Report of two cases. Asian J Neurosurg 10(2), 123-125 (2015). https://doi. org/10.4103/1793-5482.144596

Kesar, T.M., et al.: Combined effects of fast treadmill walking and functional electrical stimulation on post-stroke gait. Gait Posture 33(2), 309-313 (2011). https://doi.org/10.1016/j.gaitp ost.2010.11.019

Kluding, P.M., et al.: Foot drop stimulation versus ankle foot orthosis after stroke. Stroke 44(6), 1660-1669 (2013). https://doi. org/10.1161/strokeaha.111.000334

Koller, R.L., Blank, N.K.: Strawberry pickers' palsy. Arch. Neurol. 37(5), 320 (1980). http://www.ncbi.nlm.nih.gov/pubmed/62480 00 (Accessed: 21 October 2018)

Kottink, A.I., et al.: A Randomized controlled trial of an implantable 2-channel peroneal nerve stimulator on walking speed and activity in poststroke hemiplegia. Arch Phys Med Rehabilit (2007). https://doi.org/10.1016/j.apmr.2007.05.002

Melo, P.L., et al.: Technical developments of functional electrical stimulation to correct drop foot: sensing, actuation and control strategies. Clin Biomech 30(2), 101-113 (2015). https://doi. org/10.1016/j.clinbiomech.2014.11.007

Nakano, K.K.: Entrapment neuropathy from Baker's cyst. JAMA 239(2), 135 (1978). http://www.ncbi.nlm.nih.gov/pubmed/57937 6 (Accessed: 21 October 2018) 
NICE (2009) Functional electrical stimulation for drop foot of unctional electrical stimulation for drop foot of central neurological origin. https://www.nice.org.uk/terms-and. (Accessed: 21 October 2018)

NICE (2016) ODFS Pace and Pace XL functional electrical stimulation devices for treating drop foot. https://www.nice.org.uk/advic e/mib56/resources/odfs-pace-and-pace-xl-functional-electrical -stimulation-devices-for-treating-drop-foot-pdf-63499229886661. (Accessed: 21 October 2018)

Nobel, W.: Peroneal palsy due to hematoma in the common peroneal nerve sheath after distal torsional fractures and inversion ankle sprains. J Bone Joint Surg, Am Vol 48(8), 1484-1495 (1966). http://www.ncbi.nlm.nih.gov/pubmed/4289139. (Accessed: 21 October 2018)

Potenza, A., et al.: Foot drop in cerebral stroke: a comparison between the use of functional electrical stimulation and conventional physiotherapy. Gait Posture 35, S46 (2012). https://doi.org/10.1016/J. GAITPOST.2011.09.083

Rasool, G., et al.: Real-time task discrimination for myoelectric control employing task-specific muscle synergies. IEEE Trans Neural Syst Rehabilit Eng 24(1), 98-108 (2016). https://doi.org/10.1109/ TNSRE.2015.2410176

Ridding, M.C., et al.: Changes in muscle responses to stimulation of the motor cortex induced by peripheral nerve stimulation in human subjects. Exp Brain Res 131(1), 135-143 (2000). http://www.ncbi. nlm.nih.gov/pubmed/10759179. (Accessed: 21 October 2018)

Schrauwen, B., et al.: Compact hardware liquid state machines on FPGA for real-time speech recognition. Neural Netw 21(2-3), 511-523 (2008). https://doi.org/10.1016/j.neunet.2007.12.009

Sofla, M.A.: Identification, simulation and control of an anklefoot orthosis. vol. 435. Theses and Dissertations (2012). https://etd. ohiolink.edu/pg_10?::NO:10:P10_ETD_SUBID:2372

Spanias, J.A., et al.: Online adaptive neural control of a robotic lower limb prosthesis. J Neural Eng 15(1), 016015 (2018). https://doi. org/10.1088/1741-2552/aa92a8

Stein, R., et al.: Surface electrical stimulation for foot drop: control aspects and walking performance. J Autom Control 18(2), 47-52 (2008). https://doi.org/10.2298/JAC0802047S

Stevens, F., Weerkamp, N.J., Cals, J.W.L.: Foot drop. BMJ (2015). https://doi.org/10.1136/bmj.h1736

Stewart, J.D.: Foot drop: where, why and what to do? Pract Neurol 8(3), 158-169 (2008). https://doi.org/10.1136/jnnp.2008.149393

Suh, J.S., et al.: Peripheral (extracranial) nerve tumors: correlation of MR imaging and histologic findings. Radiology 183(2), 341-346 (1992). https://doi.org/10.1148/radiology.183.2.1561333

Taylor, P., et al.: Economic Justification for the Odstock Dropped Foot Stimulator (ODFS). http://www.odstockmedical.com/sites/defau 1t/files/cost_benefit_paper_4.pdf (2007). (Accessed: 21 October 2018)

Wen, Y., et al.: A new powered lower limb prosthesis control framework based on adaptive dynamic programming. IEEE Trans
Neural Netw Learn Syst 28(9), 2215-2220 (2017). https://doi. org/10.1109/TNNLS.2016.2584559

Woltman, H.W.: Crossing the legs as a factor in the production of peroneal palsy. J Am Med Assoc 93(9), 670 (1929). https://doi. org/10.1001/jama.1929.02710090010004

Publisher's Note Springer Nature remains neutral with regard to jurisdictional claims in published maps and institutional affiliations.

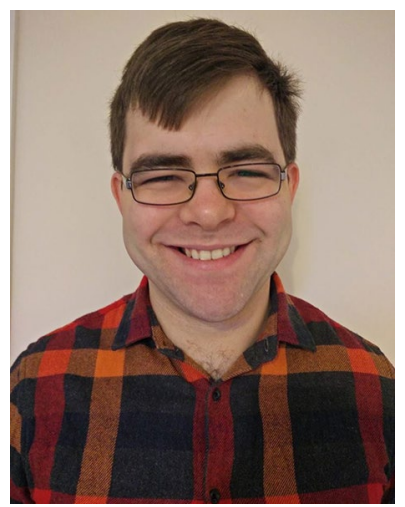

Gareth York recevied his BSc (Hons) in Biomedical Science (Neuroscience) from Cardiff University, followed by an MSc in Biophotonics also from Cardiff University. He is currently pursuing a $\mathrm{PhD}$ in brain machine interfaces for the treatment of spinal cord injury at the University of Leeds. His research interests include applying machine learning to analyse neural signals and new methods of analysing and modelling muscle synergies.

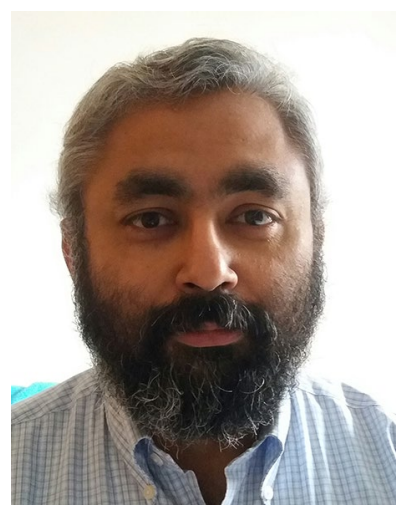

Samit Chakrabarty has been studying the role of spinal circuits in execution of motor tasks, their modulation by peripheral sensory and descending inputs from the brain, focussing on the plastic changes that the system undertakes during development or disease. After receiving his BSc in Zoology, Biochemistry from St Xavier's College, Mumbai he pursued a $\mathrm{PhD}$ in Neurophysiology of the mammalian spinal cord at the University of Cambridge, UK. This was then followed by postdoctoral training at Columbia University, NYC and University of Manitoba, Winnipeg. He has since moved to University of Leeds as an academic researcher and is active in the feld of sensory and motor control, rehabilitation and use of technology to both study and better the lives of those with maladies afecting sensory and motor function. 